\title{
Problem severity and waiting times for young people accessing mental health services
}

\author{
Julian Edbrooke-Childs and Jessica Deighton
}

\section{Background}

Access to timely care is a quality standard underpinning many international healthcare models, and long waiting times for child and adolescent mental health services are often reported as a barrier to help-seeking.

\section{Aims}

The aim of this study was to examine whether young people with more severe problems have shorter waiting times for mental health services.

\section{Method}

Multilevel multinomial regression analysis controlling for servicearea deprivation, age, gender, ethnicity, referral source and contextual factors was conducted on $N=21419$ episodes of care (mean age 12.37 years (s.d. $=3.71), 11712(55 \%)$ female) using data from child and adolescent mental health services.

\section{Results}

There was high variation in waiting times, which ranged from 0 days to 1629 days (mean 50.65 days (s.d. $=$ 78.03), median 32 days). Compared with young people with less severe problems young people with severe problems, self-harm, psychosis or eating disorders were less likely to experience longer waiting times. Moreover, referrals from sources other than primary care were generally less likely to have longer waiting times than referrals from primary care sources, especially referral from accident and emergency services.

\section{Conclusions}

The findings suggest that young people with more severe problems had shorter waiting times. Intermediary information and resources for support before access to services is needed to prevent escalation of problems and to support individuals and families while waiting for care. Interventions to reduce waiting times should be considered without compromising on the quality and experience of care that young people and families deserve when seeking help.

\section{Keywords}

Child and adolescent; mental health; waiting time; access.

\section{Copyright and usage}

(C) The Author(s), 2020. Published by Cambridge University Press on behalf of The Royal college of Psychiatrists. This is an Open Access article, distributed under the terms of the Creative commons Attribution licence (http://creativecommons.org/ licenses/by/4.0/), which permits unrestricted re-use, distribution, and reproduction in any medium, provided the original work is properly cited.

\section{Background}

Access to timely care is a quality standard underpinning many international healthcare models. It is especially important in the treatment of mental health problems as a longer duration without treatment may contribute to the development of more intractable problems. ${ }^{1}$ In England, child and adolescent mental health services are recommended to provide treatment within 2 weeks of referral for psychosis, between 2 and 4 weeks of referral for eating disorders, and within 18 weeks for all referrals. ${ }^{2}$ Recent government guidance for child and adolescent mental health services is testing a maximum waiting time of 4 weeks for routine cases and 1 week for urgent cases in some regions. ${ }^{3,4}$ It is therefore important to examine existing waiting times, how individuals are prioritised, and in particular whether young people with more severe problems have shorter waiting times.

Professionals report that waiting time is a common barrier to referring to child and adolescent mental health services and that increasing levels of demand and complexity make it ever more difficult to meet levels of need, resulting in long waiting times. ${ }^{5}$ There is anecdotal evidence that, because of limited resources and increased levels of demand, thresholds for accessing child and adolescent mental health services may have increased to prioritise those with most severe needs ${ }^{6}$ and empirical investigation of this is urgently needed.

\section{Waiting times and impact on help-seeking}

According to the gateway provider model, help-seeking agents make decisions about accessing child and adolescent mental health services based on perceptions and knowledge of the structural and systemic characteristics of their environment and their predisposing factors, levels of need and enabling factors. ${ }^{7}$ Help-seeking agents, such as young people and parents or carers, often report dissatisfaction with long waiting times for mental health services and that this is a barrier to help-seeking and accessing care, which moreover may result in deterioration and risk of problems escalating while waiting for care $^{8}$ (also see a study by Anderson et $\mathrm{al}^{9}$ for a scoping review).

Waiting times are important in relation to both initial access (for example, assessment) and start of treatment (for example, post-assessment). It is known that treatment waiting times may be particularly challenging for child and adolescent mental health services. ${ }^{10}$ Previous studies examining data from child and adolescent mental health services have found that longer waiting times were associated with lower levels of subsequent treatment engagement. ${ }^{11} \mathrm{~A}$ range of approaches have been examined to reduce waiting times, including guidance for the identification and management of mental health problems, the implementation of dedicated centres focused on assessment, and service re-design models (see a study by Ansell et $\mathrm{al}^{12}$ for a systematic review).

\section{Factors linked to waiting times}

There is a high level of heterogeneity in waiting times reported in previous studies. ${ }^{13-19}$ A recent child and adolescent mental health survey in England found that $61 \%$ of those with a mental health problem accessed specialist services in less than 10 weeks, $18 \%$ in 10 weeks to 6 months, and $21 \%$ in more than 6 months. ${ }^{20}$ Examining waiting times is complex given the number of environmental and individual characteristics related to mental health, help- 
seeking behaviour and service provision. Waiting times may differ between services and therefore, analysis needs to account for the fact that data are nested within services. Waiting times may be affected by deprivation as areas of higher deprivation may have more young people with mental health problems and lower levels of service provision.

The pattern of findings from previous studies on the association between individual characteristics and waiting times is mixed. Some studies have found that males were more likely to have longer waiting times than females or that age was negatively associated with waiting times; ${ }^{21-24}$ however, other studies have found that age was positively associated with waiting times. ${ }^{21}$ Similarly, there is conflicting evidence about whether referrals from some settings such as education are associated with longer or shorter waiting times. ${ }^{13,21}$

\section{Table 1 Descriptive statistics for study variables $(n=21419)$}

$\begin{array}{lcr}\text { Variable } & n & \% \\ \text { Service-area deprivation } & & \\ \text { IDACl band 0 } & 6858 & 32 \\ \text { IDACI band 1 } & 8750 & 41 \\ \text { IDACl band 2 } & 1312 & 6 \\ \text { IDACl band 3 } & 4499 & 21\end{array}$

Demographics

Age

$0-12$ years

$13-15$ years

$\geq 16$ years

Gender, female

Ethnicity

White British

White Other

Mixed-race

Asian

Black

Other

Not stated

Referral source ${ }^{a}$

Primary care

Self-referral

Social care/youth justice

Education

Child health

Accidence and emergency

Mental health

Other

Missing

Contextual factors

Home

School

Community

Engagement

Severity

Self-management 6363

Severe problems 1931

Self-harm 1168

Psychosis

Eating disorder

Attention-deficit hyperactivity disorder 1254

Emotional

Unclassified

Other

8858

8055

4476

11712

13505

Waiting times ${ }^{\mathrm{a}}$

0-2-week wait

3-4-week wait

5-18-week wait

$\geq 19$-week wait

IDACI, Income Deprivation Affecting Children Index.

a. Referral source and waiting times do not sum to $100 \%$ because of rounding.
Few studies have examined the association between severity and waiting times. Evidence suggests that externalising problems may be associated with longer waiting times than other types of problems $s^{23}$ (also see a study by Smith et $\mathrm{al}^{25}$ ) and that higher levels of severity are associated with shorter waiting times for attention-deficit and hyperactivity disorder (ADHD) diagnosis, ${ }^{22}$ suggesting that services may be able to appropriately triage cases with higher levels of severity. To the best of our knowledge, no previous study has examined whether young people with more severe problems have shorter waiting times for mental health services, controlling for servicelevel variation, deprivation, demographic characteristics, referral source and contextual factors.

\section{Aims}

The aim of the present study was to examine whether young people with more severe problems have shorter waiting times for mental health services. We hypothesised that young people with more severe problems would be less likely to experience longer waiting times than young people with less severe problems.

\section{Method}

\section{Participants and procedure}

The data corpus was collected from child and adolescent mental health services, including those participating in a programme to implement evidence-based practice between 2011 and 2015. ${ }^{26}$ Episodes of care were included in the present analysis if young people were aged $\leq 25$ years, had complete demographic characteristics (for example age, gender), had a referral date and a date of first contact, were referred to services between 2011 and 2015, and had complete information on problem severity (see Measures). This resulted in a final data-set of $N=21419$ episodes of care (mean age 12.37 (s.d. $=3.71$ ) years, 11712 or $55 \%$ female). It should be noted that in the data corpus, pseudonymised data are uploaded according to episodes of care; therefore, it is possible that a young person may have been included under more than one episode of care.

Detailed demographic characteristics are shown in Table 1.

\section{Ethical considerations}

The present analysis involved secondary analysis of anonymised administrative data and therefore, ethical review was not required. ${ }^{27}$

\section{Measures}

Deprivation

We matched data on services to the normalised Income Deprivation Affecting Children Index (IDACI) to generate an average score based on the lower layer super output area in each service's catchment area. Scores were then transformed into bands using the following established categories ${ }^{28}:<0.2$ (least deprived) band 0 ; $0.2-0.249$ band $1 ; 0.25-0.299$ band 2 ; and $0.3-0.4$ (most deprived) band 3 ; there were no IDACI scores $>0.4$.

\section{Demographic characteristics}

Age, gender and ethnicity were recorded by services as part of routine data recording. For the main analysis, age was coded as $13-15$ years and $\geq 16$ years (where $0-12$ years was selected as the reference category to facilitate interpretation). Ethnicity was captured using the categories from the 2001 census and was generally based on self-report by the parent/carer or the young person. These were grouped for analysis as follows: ${ }^{29}$ White British (as the ethnic majority group), White other (including Irish and other White 
background), mixed-race (including mixed White and Black Caribbean, mixed White and Black African, mixed White and Asian, and any other mixed background), Asian (including Indian, Pakistani, Bangladeshi, and other), Black or Black British (including Caribbean, African, and other), other ethnic groups (including Chinese and other), and not stated.

\section{Referral source}

As used in previous research, referral source was recorded by services using 36 indicators, which were grouped into eight study variables for the present analysis, which are shown in Table $1 .^{30}$ In the main analysis, referral from primary care was selected as the reference category as it was the largest group.

\section{Contextual factors}

Contextual factors were identified using four items of the Current View questionnaire. ${ }^{31}$ Clinicians rated the extent to which young people were experiencing problems in four contextual areas: 'Home', 'School, work or training', 'Community', and 'Service engagement' (coded 1 for 'moderate' or 'severe' and 0 for 'mild' or not applicable).

\section{Problem severity}

Problem severity was identified using an algorithm ${ }^{32,33}$ based on 30 items of the clinician-rated Current View questionnaire. ${ }^{31}$ The algorithm categorises young people into 18 mutually exclusive needsbased groups, but as there were no young people in the 'suggestive of borderline personality' group, 17 subgroups were initially used. However, to minimise including underpowered groups in the main analysis, we used nine groups and categorised those occurring with a frequency of $\leq 5 \%$ as 'other' problems (see point (i) below); 'psychosis' and 'eating disorder' were retained as separate groups despite occurring with frequencies of $\leq 5 \%$ as they were of central importance to the aims of the present research as theory and policy suggest these groups may experience shorter waiting times (see Background). The nine groups used were as follows:

(a) 'signposting and self-management advice' referring to young people for whom clinicians rated a maximum of one problem as moderate;

(b) 'difficulties of severe impact' (for example young people for whom clinicians rated at least two problems as severe);

(c) 'self-harm';

(d) 'psychosis';

(e) 'eating disorder';

(f) 'ADHD';

(g) 'emotional problems';

(h) 'difficulties not covered by other groupings' or unclassified problems; and

(i) 'other problems' (i.e. 'bipolar disorder', 'depression', 'generalised anxiety problems', 'behavioural and/or conduct disorder', 'obsessive-compulsive disorder', 'autism', 'co-occurring behavioural and emotional difficulties', 'post-traumatic stress disorder' and 'social anxiety disorder').

\section{Waiting time}

Waiting time was computed as the difference between date of referral and date of first event or contact (for example initial assessment). To enable comparison with a recent national survey, ${ }^{20}$ waiting times were grouped into: less than 10 weeks (0-69 days), 10 weeks to 6 months (70-168 days), and more than 6 months (>168 days). Based on non-mandatory guidelines, ${ }^{2}$ and given the non-normal distribution of waiting times found in the present data and previous research (see Background), waiting times were grouped for the main analysis into: 0-2-week wait (0-14 days), 3-4-week wait (15-28 days), 5-18-week wait (29-126 days), and $\geq 19$-week wait ( $\geq 127$ days).

\section{Statistical analysis}

To examine whether young people with more severe problems had shorter waiting times for mental health services, accounting for the nesting of episodes of care in services and controlling for deprivation, age, gender, ethnicity and contextual factors multilevel multinomial logistic regressions were conducted in Stata $14 .^{34}$ Four preparatory models were estimated.

In model 0 (null model) the variance explained in waiting time at the service-level was examined and no predictors were added. The intraclass correlation coefficient was $25 \%$ indicating that there was significant service-level variation in waiting times and confirming that multilevel modelling was the appropriate statistical analysis. In model 1, we examined whether service-level deprivation explained variation in waiting time using IDACI bands, where band 0 representing the lowest level of deprivation was selected as the reference group to facilitate interpretation. In model 2, demographic characteristics were added: female; age coded 13-15 and $\geq 16$ years with $0-12$ years as the reference category; and ethnicity with the White British group as the reference category as it was the largest group. In model 3, referral source was added with primary care as the reference category and the four contextual factors were added, which were dummy coded as young people's contextual factors were not mutually exclusive. Problem severity was added to the final model using the nine problem groups, where the 'Signposting and self-management advice' group was selected as the reference category as it was the largest group, referring to young people for whom clinicians rated a maximum of one problem as moderate.

The likelihood ratio test was used to compare successive models, which were significant and all variables were therefore retained in the final model. In particular, the likelihood ratio test was significant for the final model compared to model 3: $\chi^{2}(24)=336.16$, $P<0.001$.

\section{Results}

There was high variation in waiting times, which ranged from 0 days to 1629 days (mean 50.65 days (s.d. $=78.03$ ), median 32 days). Overall, 16737 (78\%) young people waited less than 10 weeks, 3902 (18\%) waited between 10 weeks and 6 months and 780 (4\%) waited more than 6 months. The results of the final model (with problem severity in addition to service-level deprivation, demographic characteristics, referral source and contextual factors) are shown in Table 2.

Compared with boys, girls were less likely to wait 5-18 weeks and $\geq 19$ weeks than $0-2$ weeks. Compared with young people aged $0-12$ years, young people aged $13-15$ years or $\geq 16$ years were less likely to wait 3-4 weeks, 5-18 weeks and $\geq 19$ weeks than $0-2$ weeks. Compared with White British young people, Asian young people were less likely to wait 3-4 weeks and $\geq 19$ weeks than 0-2 weeks. Compared with White British young people, Black young people were less likely to wait 3-4 weeks and 5-18 weeks than 0-2 weeks. Compared to White British young people, young people from 'other' ethnic backgrounds were less likely to wait $3-4$ weeks and $\geq 19$ weeks than $0-2$ weeks. Compared with White British young people, young people with not stated ethnic backgrounds were more likely to wait 3-4 weeks than $0-2$ weeks.

Referrals from sources other than primary care were consistently less likely to have longer waiting times than referrals from 
Table 2 Multilevel multinomial regression analysis: service-area deprivation, demographics, referral source, contextual factors and severity predicting waiting times $(N=21419)^{\mathrm{a}}$

\begin{tabular}{|c|c|c|c|c|c|c|c|c|c|}
\hline & \multicolumn{3}{|c|}{$\begin{array}{c}\text { 3-4-week v. 0-2 week } \\
\text { wait }\end{array}$} & \multicolumn{3}{|c|}{$\begin{array}{c}\text { 5-18-week v. 0-2-week } \\
\text { wait }\end{array}$} & \multicolumn{3}{|c|}{$\geq 19$-week v. 0-2-week wait } \\
\hline & OR & \multicolumn{2}{|c|}{$95 \% \mathrm{Cl}$} & OR & \multicolumn{2}{|c|}{$95 \% \mathrm{Cl}$} & $\mathrm{OR}$ & \multicolumn{2}{|c|}{$95 \% \mathrm{Cl}$} \\
\hline \multicolumn{10}{|l|}{ Service-area deprivation } \\
\hline IDACI band 1 V. 0 & 0.89 & 0.47 & 1.71 & 1.08 & 0.56 & 2.06 & 1.78 & 0.92 & 3.44 \\
\hline IDACI band 2 v. 0 & 0.82 & 0.33 & 2.02 & 1.15 & 0.47 & 2.81 & 2.32 & 0.93 & 5.80 \\
\hline IDACI band $3 v .0$ & 0.68 & 0.28 & 1.68 & 0.95 & 0.39 & 2.33 & 0.72 & 0.29 & 1.79 \\
\hline \multicolumn{10}{|l|}{ Demographics } \\
\hline Female $v$. male & 0.95 & 0.86 & 1.04 & 0.90 & 0.83 & 0.97 & 0.76 & 0.67 & 0.86 \\
\hline $13-15$ v. 0-12 years & 0.64 & 0.57 & 0.71 & 0.52 & 0.48 & 0.57 & 0.52 & 0.45 & 0.60 \\
\hline$\geq 16 \mathrm{v} .0-12$ years & 0.60 & 0.53 & 0.68 & 0.42 & 0.38 & 0.47 & 0.36 & 0.30 & 0.43 \\
\hline White other $v$. White British & 0.92 & 0.72 & 1.18 & 1.08 & 0.88 & 1.33 & 1.23 & 0.89 & 1.69 \\
\hline Mixed-race $v$. White British & 0.98 & 0.77 & 1.25 & 1.11 & 0.90 & 1.37 & 1.00 & 0.71 & 1.41 \\
\hline Asian v. White British & 0.63 & 0.50 & 0.78 & 0.92 & 0.76 & 1.10 & 0.63 & 0.45 & 0.87 \\
\hline Black v. White British & 0.55 & 0.42 & 0.71 & 0.77 & 0.63 & 0.94 & 1.16 & 0.86 & 1.56 \\
\hline Other v. White British & 0.70 & 0.53 & 0.94 & 0.91 & 0.72 & 1.15 & 0.52 & 0.33 & 0.82 \\
\hline Not stated $v$. White British & 1.34 & 1.17 & 1.53 & 1.03 & 0.91 & 1.16 & 0.87 & 0.73 & 1.04 \\
\hline \multicolumn{10}{|l|}{ Referral source and contextual factors } \\
\hline Self $v$. primary & 0.56 & 0.45 & 0.69 & 0.49 & 0.41 & 0.58 & 0.88 & 0.68 & 1.15 \\
\hline Social care/youth justice $v$. primary & 0.50 & 0.40 & 0.63 & 0.41 & 0.34 & 0.49 & 0.38 & 0.28 & 0.53 \\
\hline Education v. primary & 0.83 & 0.70 & 0.98 & 0.61 & 0.52 & 0.70 & 0.40 & 0.31 & 0.52 \\
\hline Child health $v$. primary & 0.83 & 0.66 & 1.03 & 0.86 & 0.71 & 1.03 & 0.99 & 0.76 & 1.29 \\
\hline Accident and Emergency $v$. primary & 0.14 & 0.12 & 0.18 & 0.10 & 0.08 & 0.12 & 0.12 & 0.08 & 0.17 \\
\hline Mental health v. primary & 0.41 & 0.35 & 0.49 & 0.42 & 0.37 & 0.49 & 0.82 & 0.68 & 1.00 \\
\hline Other $v$. primary & 0.67 & 0.57 & 0.79 & 0.68 & 0.59 & 0.78 & 0.48 & 0.38 & 0.60 \\
\hline Missing $v$. primary & 0.70 & 0.58 & 0.84 & 0.35 & 0.30 & 0.42 & 0.17 & 0.12 & 0.23 \\
\hline Home & 0.93 & 0.84 & 1.04 & 0.96 & 0.88 & 1.05 & 1.07 & 0.92 & 1.24 \\
\hline School & 1.02 & 0.91 & 1.14 & 0.94 & 0.86 & 1.03 & 1.00 & 0.86 & 1.16 \\
\hline Community & 1.03 & 0.88 & 1.20 & 1.10 & 0.97 & 1.26 & 0.83 & 0.67 & 1.03 \\
\hline Engagement & 0.83 & 0.68 & 1.03 & 0.78 & 0.65 & 0.93 & 1.09 & 0.82 & 1.46 \\
\hline \multicolumn{10}{|l|}{ Severity } \\
\hline Severe problems $v$. self-management & 0.79 & 0.67 & 0.94 & 0.73 & 0.63 & 0.84 & 0.74 & 0.59 & 0.94 \\
\hline Self-harm v. self-management & 0.48 & 0.40 & 0.58 & 0.35 & 0.29 & 0.41 & 0.29 & 0.21 & 0.42 \\
\hline Psychosis v. self-management & 0.53 & 0.37 & 0.78 & 0.39 & 0.28 & 0.54 & 0.29 & 0.14 & 0.61 \\
\hline Eating disorder $v$. self-management & 1.02 & 0.78 & 1.35 & 0.51 & 0.39 & 0.67 & 0.46 & 0.26 & 0.80 \\
\hline ADHD $v$. self-management & 1.32 & 1.05 & 1.67 & 1.66 & 1.36 & 2.03 & 1.76 & 1.35 & 2.31 \\
\hline Emotional problems $v$. self-management & 1.13 & 0.95 & 1.34 & 1.18 & 1.02 & 1.37 & 1.07 & 0.85 & 1.35 \\
\hline Unclassified problems $v$. self-management & 0.95 & 0.82 & 1.09 & 0.97 & 0.86 & 1.10 & 0.91 & 0.76 & 1.10 \\
\hline Other $v$. self-management & 0.93 & 0.82 & 1.06 & 1.01 & 0.90 & 1.12 & 0.87 & 0.73 & 1.03 \\
\hline
\end{tabular}

primary care sources, except for referrals from child health (and self-referrals when comparing $\geq 19$-week wait to 0 -2-week wait) which were not significantly different. In particular, compared with referrals from primary care sources, referrals from accident and emergency services were less likely to wait 3-4 weeks, 5-18 weeks, and $\geq 19$ weeks compared with $0-2$ weeks. Compared with young people without contextual problems in service engagement, young people with contextual problems in service engagement were less likely to wait 5-18 weeks than 0-2 weeks.

The hypothesis that young people with more severe problems would have shorter waiting times for mental health services than young people with less severe problems was supported. Compared with young people in the signposting and self-management advice group, young people with severe problems, self-harm, and psychosis were less likely to wait 3-4 weeks, 5-18 weeks and $\geq 19$ weeks than $0-2$ weeks. In addition, compared with young people in the signposting and self-management advice group, young people with eating disorders were less likely to wait 5-18 weeks and $\geq 19$ weeks than 0-2 weeks. Finally, compared with young people in the signposting and self-management advice group, young people in the ADHD group were more likely to wait 3-4 weeks, 5-18 weeks, and $\geq 19$ weeks than $0-2$ weeks, and young people in the emotional problems group were more likely to wait 5-18 weeks than $0-2$ weeks.

\section{Discussion}

The aim of the present study was to examine whether young people with more severe problems had shorter waiting times for mental health services, using multilevel multinomial regression analysis controlling for service-area deprivation, age, gender, ethnicity, referral source and contextual factors. We hypothesised that young people with more severe problems would be less likely to have longer waiting times than young people with less severe problems.

\section{Main findings and comparison with findings from other studies}

In line with previous studies, there was a high level of heterogeneity in waiting times. ${ }^{13-19}$ We found shorter waiting times than reported in a recent child and adolescent mental health survey - in the present study, 16737 (78\%) young people waited less than 10 weeks, $3902(18 \%)$ waited between 10 weeks and 6 months, and 780 (4\%) waited more than 6 months - although it should be noted that different methodologies including operationalisations of waiting times were used. ${ }^{20}$ The hypothesis that young people with more severe problems would have shorter waiting times for 


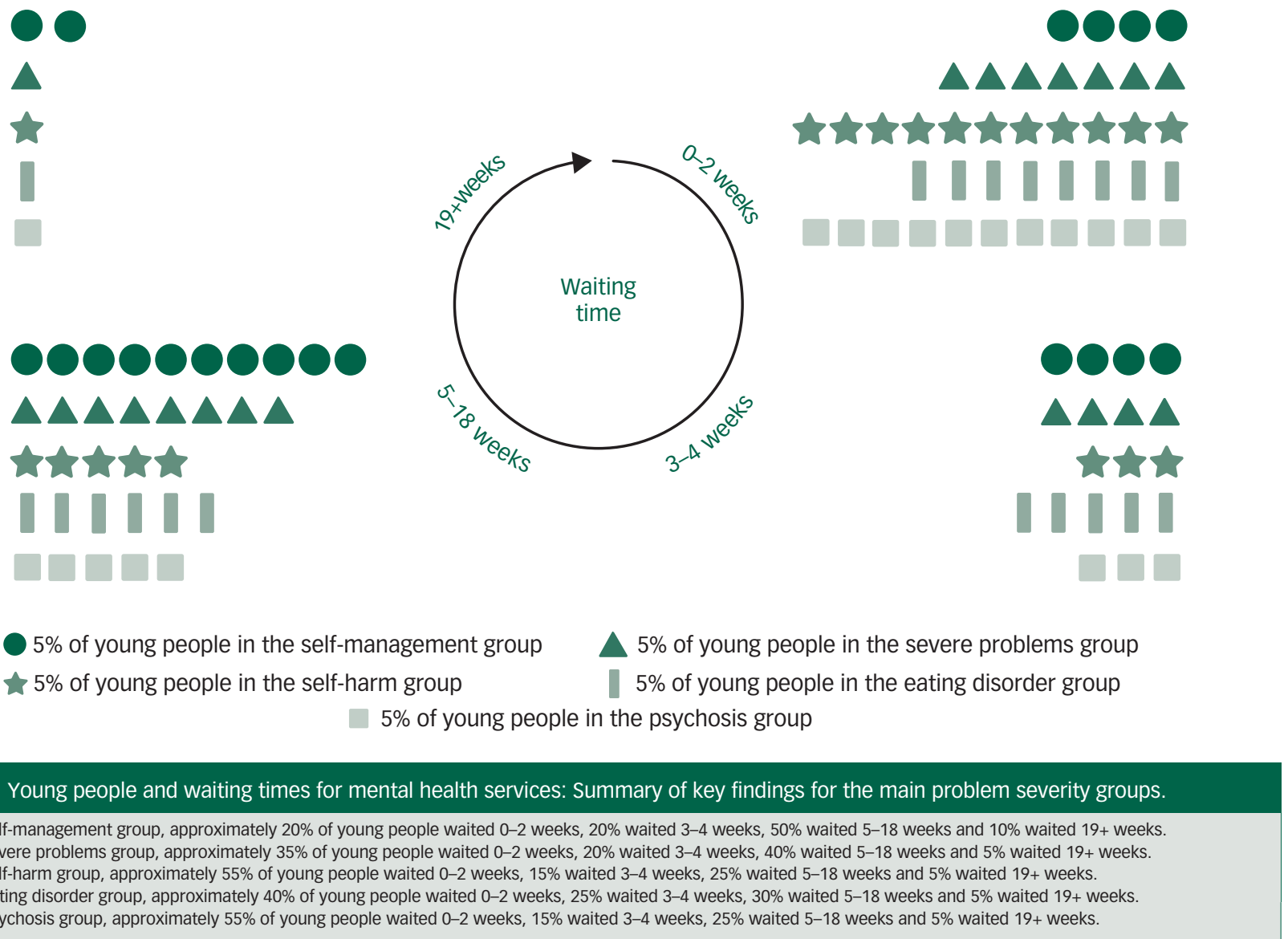

mental health services than young people with less severe problems was supported.

Compared with young people in the signposting and self-management advice group, where clinicians rated a maximum of one problem as moderate, young people with severe problems, selfharm and psychosis were less likely to have longer waiting times. In addition, compared with young people in the signposting and self-management advice group, young people with eating disorders were generally less likely to have longer waiting times.

Finally, compared with young people in the signposting and selfmanagement advice group, young people in the ADHD and emotional problems groups were more likely to have longer waiting times.

The findings of the present research are in line with previous studies suggesting that externalising problems may be associated with longer waiting times than other types of problems ${ }^{23}$ (also see a study by Smith et $\mathrm{al}^{25}$ ) and that higher levels of severity are associated with short waiting times for ADHD diagnosis when examining only those with $\mathrm{ADHD}^{22}$ (although in comparison with the self-management group in the present study, young people with ADHD were more likely to have longer waiting times). ${ }^{22}$ Moreover, the findings that young people with psychosis were less likely to wait 3-4 weeks, 5-18 weeks, and $\geq 19$ weeks, and that young people with eating disorders were less likely to wait $5-18$ weeks and $\geq 19$ weeks, are in line with recommendations for child and adolescent mental health services in England to provide treatment within 2 weeks of referral for psychosis and between 2 and 4 weeks of referral for eating disorders. $^{2}$

\section{Source of referrals}

Referrals from sources other than primary care were consistently less likely to have longer waiting times than referrals from primary care sources, with some exceptions (see Results). In particular, compared with referrals from primary care sources, referrals from accident and emergency services were less likely to wait 3-4 weeks, 5-18 weeks, and $\geq 19$ weeks compared with $0-2$ weeks. These findings suggest a pattern of crisis responsiveness, in line with the findings that young people with more severe problems had shorter waiting times for mental health services.

\section{Waiting times and ethnicity}

In addition, in some instances, young people from minority ethnic groups were less likely to have longer waiting times, which is in line with evidence that young people from minority ethnic groups are more likely to access mental health services through routes that are less likely to be voluntary. ${ }^{30}$

\section{Limitations}

The present research addresses an important gap in the literature on whether young people with more severe problems have shorter waiting times for mental health services, controlling for service-level variation, deprivation, demographic characteristics, referral source and contextual factors. Nevertheless, limitations should be considered when interpreting the findings of the present research. The data were routinely collected from child and adolescent mental health services and were collected from one country. In particular, the aim of the present study was to examine whether young people with more severe problems have shorter waiting times for mental health services. In the present research, it was not possible to examine whether waiting times differed pre- or post-assessment, and one reason for the lower waiting times found in the present research may be that they do not 
represent post-assessment waiting times, which may be particularly challenging for child and adolescent mental health services. ${ }^{10}$

In addition, findings may not generalise to other countries, especially with different policies and targets on waiting times and referral routes to child and adolescent mental health services. We controlled for a number of factors based on past theory and research (see Background); however, it is possible that other environmental and individual characteristics may explain the pattern of findings and are associated with severity and waiting times.

\section{Further research}

Importantly, in the present research we examined problem severity based on clinician ratings, and it is crucial to review whether the findings of the present research are in line with the views and lived experiences of help-seeking agents, particularly young people and parents or carers. One research question of particular interest is whether young people's self-reported levels of need, risk and distress at time of referral are associated with differential waiting times. Moreover, interventions to reduce waiting times may result in worse treatment outcomes and experiences if they are not evidence-based and informed by clinical and lived expertise. A multifaceted approach to reducing waiting times is needed that additionally accounts for improving treatment outcomes and experiences.

\section{Implications}

The findings of the present research and the extant literature suggest that young people with more severe problems have shorter waiting times compared with young people with less severe problems. The findings of the present research build on anecdotal evidence that thresholds for accessing child and adolescent mental health services may have increased to prioritise those with most severe needs. ${ }^{6}$ Intermediary information and resources for support before access to services is needed to prevent escalation of problems and to support individuals and families while waiting for care, especially considering that individuals and families may be experiencing problems that are subjectively far from 'less severe'.

Information and resources could include online-supported selfmanagement, access to voluntary or third-sector organisations, or signposting to support not accompanied by a professional (for example community, peer or family support).$^{35}$ In addition, complimentary pathways for the early identification of difficulties at an early stage of development or presentation are needed, as findings from the present research suggest that these young people may be more likely to have longer waiting times for mental health services. Although it is clearly important to prioritise those with high need, it is also important to not miss opportunities for early intervention for those with emerging difficulties, as this may be when the biggest impact might be seen from intervention. ${ }^{1}$ Primary prevention at the levels of universal, targeted to disproportionally affected groups, and those experiencing emerging difficulties, in addition to mental health promotion that focuses on empowering all young people with the resources to actively manage their mental health, are crucial parts of this continuum of care. Any interventions and approaches to reducing waiting times should be considered without compromising on the quality and experience of care that young people and families deserve when seeking help.

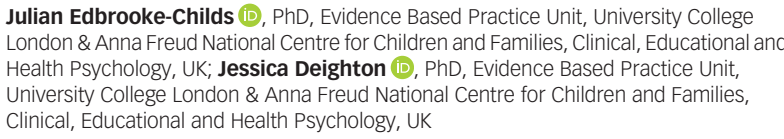

First received 2 Jan 2020, final revision 23 Aug 2020, accepted 4 Sep 2020

\section{Data availability}

The data that support the findings of this study are available on request from the corresponding author, J.E.-C. The data are not publicly available due to license for use for the present study from the Child Outcomes Research Consortium (CORC).

\section{Acknowledgements}

The authors would like to thank all members of CORC, its committee at the time of writing including: Ashley Wyatt, Mick Atkinson, Kate Martin, Ann York, Duncan Law, Julie Elliot, Isobel Fleming, Beth Ingram - and the CORC team at the time of writing (including J.E.-C.): Kate Dalzell, Benjamin Richie, Jenna Jacob, Luís Costa Da Silva, Alison Ford, Sally Marriott, Lee Atkins, Martha Reilly, Nicholas Tait, Anja Teichert, Rory Lawless, Anisatu Rashid, Sophie D'Souza and Rebecca Lane. The authors would also like to thank Miranda Wolpert for helpful comments on an earlier draft.

\section{Author contributions}

J.E.-C. and J.D. conceived of the study, drafted the manuscript and approved the final version to be published; J.E.-C. analysed the data with supervision of J.D.

\section{Funding}

The research was supported by the National Institute for Health Research (NIHR) Collaboration for Leadership in Applied Health Research and Care (CLAHRC) North Thames at Bart's Health NHS Trust. The views expressed are those of the authors and not necessarily those of the NHS, the NIHR or the Department of Health and Social Care.

\section{Declaration of interest}

J.E.-C. reports grants from NHS England \& NHS Improvement, outside the submitted work; and J.E.-C. was involved in the programme of service transformation that this report draws on. J.D. has nothing to disclose.

\section{References}

1 Colizzi M, Lasalvia A, Ruggeri M. Prevention and early intervention in youth mental health: is it time for a multidisciplinary and trans-diagnostic model for care? Int J Ment Health Syst 2020; 14: 23.

2 Care Quality Commission. Brief Guide: Waiting Times for Community Child and Adolescent Mental Health Services. Care Quality Commission, 2017.

3 Department of Health. Department of Education. Transforming Children and Young People's Mental Health Provision: A Green Paper. Department of Health, Department for Education, 2017.

4 Parkin E, Bellis A. NHS Maximum Waiting Times Standards and Patient Choice Policies. House of Commons Library, 2018.

5 Bridgemohan C, Bauer NS, Nielsen BA, DeBattista A, Ruch-Ross HS, Paul LB, et al. A workforce survey on developmental-behavioral pediatrics. Pediatrics 2018; 141: e20172164.

6 Care Quality Commission. Are we Listening? Review of Children and Young People's Mental Health Services. Care Quality Commission, 2018.

7 Stiffman AR, Pescosolido B, Cabassa $L$. Building a model to understand youth service access: the gateway provider model. Ment Health Serv Res 2004; 6 : 189-98.

8 YoungMinds. A New Era for Young People's Mental Health. YoungMinds, 2019.

9 Anderson JK, Howarth E, Vainre M, Jones PB, Humphrey A. A scoping literature review of service-level barriers for access and engagement with mental health services for children and young people. Child Youth Serv Rev 2017; 77: 164-76.

10 Moore A, Gammie J. Revealed: Hundreds of Children Wait More than a Year for Specialist Help. Health Service Journal 2018 (https://www.hsj.co.uk/qualityand-performance/revealed-hundreds-of-children-wait-more-than-a-year-forspecialist-help/7023232.article).

11 Westin AM, Barksdale CL, Stephan SH. The effect of waiting time on youth engagement to evidence based treatments. Community Ment Health J 2014; 50: $221-8$

12 Ansell D, Crispo JAG, Simard B, Bjerre LM. Interventions to reduce wait times for primary care appointments: a systematic review. BMC Health Serv Res 2017; 17: 295 .

13 Foreman DM. The impact of governmental guidance on the time taken to receive a prescription for medication for ADHD in England. Child Adolesc Ment Health 2010; 15: 12-7.

14 Rickwood DJ, Telford NR, Mazzer KR, Parker AG, Tanti CJ, McGorry PD. The services provided to young people through the headspace centres across Australia. Med J Aust 2015; 202: 533-6.

15 McNicholas F, Reulbach U, Hanrahan SO, Sakar M. Are parents and children satisfied with CAMHS? Ir J Psychol Med 2016; 33: 143-9. 
16 Church $\mathrm{H}$. Child and adolescent mental health services in Laois/Offaly: a one year perspective of services (July 1, 2008 to June 30, 2009). Ir J Psychol Med 2012; 29: 107-12.

17 Schraeder KE, Reid GJ. Why wait? The effect of wait-times on subsequent helpseeking among families looking for children's mental health services. J Abnorm Child Psychol 2015; 43: 553-65.

18 Day C, Davis H. The effectiveness and quality of routine child and adolescent mental health care outreach clinics. Br J Clin Psychol 2006; 45: 439-52.

19 Frith E. Access and Waiting Times in Children and Young People's Mental Health Services. Education Policy Institute, 2017.

20 NHS Digital. Mental Health of Children and Young People in England, 2017. NHS Digital, 2018.

21 Gallucci G, Swartz W, Hackerman F. Impact of the wait for an initial appointment on the rate of kept appointments at a mental health center. Psychiat Serv 2005; 56: 344-6.

22 Bonati M, Cartabia M, Zanetti M, Lombardy AG. Waiting times for diagnosis of attention-deficit hyperactivity disorder in children and adolescents referred to Italian ADHD centers must be reduced. BMC Health Serv Res 2019; 19: 673

23 Andersson HW. Factors associated with waiting time for access to mental health services for children and adolescents in Norway. Child Care in Practice 2010; 10: 47-56.

24 Kriz S, Thomsen PH. Doubling of the capacity of child psychiatric services in a region of southwestern Norway-how did it affect the composition of the clinical population? Nord J Psychiatry 2009; 63: 322-30.

25 Smith J, Kyle RG, Daniel B, Hubbard G. Patterns of referral and waiting times for specialist Child and Adolescent Mental Health Services. Child Adolesc Ment Health 2017; 23: 41-9.

26 Wolpert M, Jacob J, Napoleone E, Whale A, Calderon A, Edbrooke-Childs J. Child- and Parent-reported Outcomes and Experience from Child and Young People's Mental Health Services 2011-2015. CAMHS Press, 2016.
27 National Health Service Health Research Authority. Governance Arrangements for Research Ethics Committees (GAfREC). NHS HRA, 2018.

28 Department for Education. Schools Block National Funding Formula: Tehnical Note. Department for Education, 2018.

29 Edbrooke-Childs J, Newman R, Fleming I, Deighton J, Wolpert M. The association between ethnicity and care pathway for children with emotional problems in routinely collected child and adolescent mental health services data. Eur Child Adolesc Psychiatry 2015; 25: 539-46.

30 Edbrooke-Childs J, Patalay P. Ethnic differences in referral routes to youth mental health services. J Am Acad Child Adolesc Psychiatry 2019; 58: 368-75.e1.

31 Jones M, Hopkins K, Kyrke-Smith R, Davies R, Vostanis P, Wolpert M. Current View Tool: Completion Guide. CAMHS Press, 2013.

32 Wolpert M, Vostanis P, Young S, Clark B, Davies R, Fleming I, et al. Child and Adolescent Mental Health Services Payment System Project: Final Report. CAMHS Press, 2015.

33 Martin $P$, Davies $R$, Macdougall A, Ritchie $B$, Vostanis $P$, Whale $A$, et al. Developing a case mix classification for child and adolescent mental health services: the influence of presenting problems, complexity factors and service providers on number of appointments. J Ment Health 2020; 29: 431-8.

34 StataCorp. Stata Statistical Software: Release 12. StataCorp LP, 2011

35 Wolpert M, Dalzell K, Ullman R, Garland L, Cortina M, Hayes D, et al. Strategies not accompanied by a mental health professional to address anxiety and depression in children and young people: a scoping review of range and a systematic review of effectiveness. Lancet Psychiatry 2019; 6: 46-60. 